\title{
Long-term biological effects of petroleum residues on fiddler crabs in salt marshes
}

\author{
Jennifer B. Culbertson ${ }^{* 1,2}$, Ivan Valiela ${ }^{1}$, Emily E. Peacock ${ }^{1,2}$, Christopher M. Reddy ${ }^{2}$, Anna \\ Carter $^{1}$, Rachel VanderKruik ${ }^{1}$ \\ ${ }^{1}$ Boston University Marine Program, Marine Biological Laboratory, 7 MBL Street, Woods \\ Hole, MA, USA \\ ${ }^{2}$ Department of Marine Chemistry and Geochemistry, Woods Hole Oceanographic \\ Institution, Woods Hole, MA, USA \\ * Corresponding author phone: 508-289-7647; fax: 508-289-7949; e-mail: \\ jbculber@bu.edu
}

In September 1969, the Florida barge spilled 700,000 L of No. 2 fuel oil into the salt marsh sediments of Wild Harbor (Buzzards Bay, MA). Today the aboveground environment appears unaffected, but a substantial amount of moderately degraded petroleum still remains 8 to $20 \mathrm{~cm}$ below the surface. The salt marsh fiddler crabs, Uca pugnax, which burrow into the sediments at depths of 5 to $25 \mathrm{~cm}$, are chronically exposed to the spilled oil. Behavioral studies conducted with $U$. pugnax from Wild Harbor and a control site, Great Sippewissett marsh, found that crabs exposed to the oil avoided burrowing into oiled layers, suffered delayed escape responses, lowered feeding rates, and lower densities. The oil residues are therefore biologically active and affect $U$. pugnax populations. Our results add new knowledge about long-term consequences of spilled oil, a dimension that should be 
included when assessing oil-impacted areas and developing management plans designed to restore, rehabilitate, or replace impacted areas.

Keywords: Oil pollution; Fiddler crabs; salt marsh; No. 2 fuel oil; Florida; petroleum hydrocarbons

\section{Introduction}

In 2003, the National Research Council published Oil in the Sea III, a widely respected report that highlights priority areas for oil spill research (NRC, 2003). Cited as a "high priority" is the study of "chronic biological effects resulting from the persistence of medium and high molecular weight aromatic hydrocarbons and heterocyclic compounds and their degradation products in sediments...". We have extensive information on acute effects of spilled oil on marine ecosystems and populations, but the lingering effect of longterm exposure to petroleum hydrocarbons remains one of the largest unknowns (Burns and Teal, 1971; Sanders et al., 1972; Teal et al., 1992). For example, it is considerably easier to detect oil residues in salt marsh sediments (Reddy et al., 2002; Peacock et al., 2005; Peacock et al., 2007) than to document ecosystem impacts resulting from these contaminants (Peterson et al., 2003).

In September 1969, the barge Florida (Fig. 1) ran aground in Buzzards Bay, Massachusetts and spilled 700,000 L of No. 2 fuel oil. Spilled oil entered Wild Harbor and killed large quantities of fish, crustaceans, worms, mollusks, other invertebrates and Spartina grasses (Fig. 2a,b) (Blumer and Sass 1972a,b ; Blumer et al., 1970; Burns and Teal 1971; Sanders et al., 1972; Teal et al., 1992). Many studies over the past 37 years have shown that despite the continued presence of residual oil in these marsh sediments the vegetation and much of the fauna recovered (Burns and Teal, 1971; Frysinger et al., 2003; Peacock et al., 2005; Reddy et al., 2002; Sanders et al., 1972; Slater et al., 2005; Teal et al., 
1978; Teal et al., 1992 White et al. 2005a, b). Today, the marsh vegetation surrounding Wild Harbor (Fig. 2c) appears no different from nearby marshes that were not oiled.

Recent work found that a substantial residue of the No. 2 fuel oil was still present 8 to $20 \mathrm{~cm}$ below the salt marsh surface (Fig. 3b) across Wild Harbor (Frysinger et al., 2003; Reddy et al., 2002; Slater et al., 2005; White et al. 2005a, b; Peacock et al., 2005). The oiled sediments are now overlain by subsequent accretion, about $0.35 \mathrm{~cm} \mathrm{yr}^{-1}$, of salt marsh sediments devoid of oil (White et al., 2005a). Despite slight differences in analytical methods, the concentrations of residual total petroleum hydrocarbons (TPHs) within the 8 to $20 \mathrm{~cm}$ layer, for sediment collected in 2000 , were in roughly the same range as those measured in 1973 in surface sediments (Reddy et al., 2002). The petroleum hydrocarbons present at depth are moderately degraded: volatile and water-soluble compounds and $n$ alkanes have been removed, concentrations of acyclic isoprenoids have been reduced, but alkyl cyclohexanes, alkylbenzenes, and polycyclic aromatic hydrocarbons (PAHs) as well as many other unidentified hydrocarbons still persist (Reddy et al., 2002; Frysinger et al., 2003; White et al., 2005). In particular, total PAHs (mostly alkylated naphthalenes and phenanthrenes/anthracenes) in a core collected in 2000 were $134 \mathrm{~g} \mathrm{~g}^{-1}$ in the $14-16 \mathrm{~cm}$ horizon (White et al., 2005b); such levels are very similar to concentrations of PAHs found in the 1970s (Blumer and Sass, 1972). This current PAH content is 40x greater than thresholds thought to be associated with the incidence of biological effects (Long et al., 1995), assuming that the biological response for parent and alkylated PAHs is the same. Therefore, petroleum hydrocarbons from the Florida spill persist, at remarkable concentrations, at depth in the anoxic sediments in some areas of Wild Harbor (Teal et al., 1992; Reddy et al., 2002; White et al. 2005b; Peacock et al., 2005).

Here we investigate and report whether this oil, after being spilled almost four decades ago, affects the burrowing behavior, escape response, feeding rate, population 
genetics, and abundance of fiddler crabs. The continued presence, and extensive datasets, of the residual oil in Wild Harbor presents an unusual opportunity to assess ecological effects of chronic exposure to petroleum residues. We selected the salt marsh fiddler crab, Uca pugnax, as a model organism for examining potential long-term biological effects of the residual oil because previous work showed acute impacts on U. pugnax in this ecosystem (Krebs and Burns, 1977). In addition, U. pugnax burrows extend into sediments down to a depth of $30 \mathrm{~cm}$ (Montague, 1980). This behavior potentially exposes the crabs to the oiled sediment layer in Wild Harbor.

\section{Methods}

\subsection{Study and control sites}

We performed a series of experiments, in the summer of 2005 and 2006, using $U$. pugnax from Wild Harbor and Great Sippewissett salt marsh. The latter is a neighboring salt marsh that has similar flora, fauna, sediments, and geological history (Krebs and Burns 1977). In addition, using routine methods (Reddy et al., 2002), we found no detectable oil residues in sediment cores collected at this site in 2006. In this study and as in the past, we assume that most of the hydrocarbons in our operationally defined TPHs are from the Florida spill and consist mainly of an unresolved complex mixture (UCM) in the boiling

range from $n-\mathrm{C}_{10}$ to $n-\mathrm{C}_{26}$ alkanes. Our estimated method detection limit is $0.0015 \mathrm{mg}$ of TPH g-1 of dry sediment (Reddy et al., 2002).

\subsection{Burrowing behavior}

To measure the burrow depth, we made casts of burrow structures by pouring liquefied Plaster of Paris into 19 crab burrows in Wild Harbor and in 12 burrows of Great Sippewissett marsh. These burrows are easy to identify by the appearance of the burrow 
opening and their location in the low marsh (Montague 1980). The burrow casts were removed $24 \mathrm{~h}$ later.

One particular advantage of this study was that Peacock et al. (2005) analyzed 26 sediment cores at Wild Harbor from 2002 to 2004 and modeled the oil content over a 300 $\mathrm{m}^{2}$ area. This model assumed that the oil content in each core was homogeneous within one square meter. Furthermore on the basis of analyzing the data, we hypothesized that the mean oil content declined exponentially from an area impacted with the highest levels of TPHs. Please note that Peacock et al. (2005) chose to model the total oil in the top $24 \mathrm{~cm}$ in $\mathrm{g} \mathrm{m}^{-2}$ instead of oil concentration in $\mathrm{mg} \mathrm{g}^{-1}$ because the approach avoided problems with the coarse resolution at which these sediment cores were split $(4 \mathrm{~cm})$ and compaction (Peacock et al., 2005). With these results, the latter authors then mapped the total oil content in Wild Harbor in $\mathrm{g} \mathrm{m}^{-2}$. Hence, this allowed us to compare burrow depth in locations that ranged in known oil content.

\subsection{Escape response}

To assess whether exposure to oil residues found in Wild Harbor sediments affected the escape response of $U$. pugnax, with previous long-term exposure and without long-term exposure, we fed crabs from Wild Harbor (the oiled marsh) and Great Sippewissett (the non-oiled marsh) reciprocally with sediment collected from each marsh. We placed crabs from Wild Harbor $(n=120)$ and Great Sippewissett $(n=120)$ marsh in separate containers, where we also placed sections of cores from depths of 0 to $4 \mathrm{~cm}$ (nonoiled), 12 to $16 \mathrm{~cm}$ (oiled), and 20 to $24 \mathrm{~cm}$ (non-oiled), and we allowed the crabs to consume sediment material replacing the sediment every 3 days (Table 1). Fiddler crabs feed by scraping off portions of sediment and sifting through it with complex mouthparts, consuming the organic matter, and rejecting the remnants in the form of pseudofeces 
(Daiber, 1982). We included core sections from above and below the oiled layer because we not only wanted to compare non-oiled and oiled layers, but also were concerned that there might be differences in feeding rates (and other behavioral responses) that were associated to differences in the percentage of bulk nitrogen $(\mathrm{N})$, a feeding cue, found in vertical profiles of marsh sediment (Valiela, 1995). Comparing the response of crabs exposed to the layer above and below the oiled layer allowed us to separate the effects of $\% \mathrm{~N}$ and oil. Nitrogen content was measured on 1 to $2 \mathrm{~g}$ samples from each core. The sediment was dried at 60 ${ }^{\circ} \mathrm{C}$ for $7 \mathrm{~d}$ and then analyzed on a Perkin-Elmer CHN Elemental Analyzer.

After $10 \mathrm{~d}$ of active feeding by the crabs on the different sediment types, we measured the behavioral escape response of each crab. These trials consisted of exposure of each crab to a standard visual stimulus, a 5 x $5 \mathrm{~cm}$ weighted black square, which swung across the visual field of a crab every $0.5 \mathrm{~s}$. The time each crab took to exit a $44-\mathrm{cm}$ diameter circle drawn on the bottom of the test arena was recorded with a maximum observation time of $120 \mathrm{~s}$ (Krebs et al., 1974).

\subsection{Feeding rate}

To evaluate whether feeding rates were affected by exposure to oil, we measured fecal pellet production as a proxy for feeding rate in the same group of crabs used in the escape response study (Krebs and Valiela, 1978). We counted pellets every $12 \mathrm{hrs}$ for each treatment combination using the same layout design as in the escape response work, taking care to distinguish fecal pellets from pseudofeces. Once counted, the fecal pellets were destroyed to avoid recounting.

\subsection{Abundance}


To determine if there were differences in abundances of crabs between oiled and non-oiled sites, we surveyed abundance of $U$. pugnax in transects over each of the two marshes, with transects covering the tidal excursion within which crabs were found $(n=10)($ Krebs and Burns, 1977). In each transect, we counted the number of burrows (per $0.5 \mathrm{~m}^{2}$ ) as a proxy for crab abundance (Krebs and Valiela, 1978).

\section{Results and discussion}

\subsection{Burrowing behavior}

Burrows made by crabs in oiled Wild Harbor sediments were shallower (mean depth \pm s.e. $=6.8 \pm 0.6 \mathrm{~cm}, n=18)$ than those in Great Sippewissett marsh (mean depth \pm s.e. $=14.8 \pm 1.0 \mathrm{~cm}, n=10)(\mathrm{t}$-test, $\mathrm{t}$ stat=-7.66, $P<0.001)($ Fig. $4 \mathrm{a})$. Great Sippewissett marsh has no detectable oil in it. Median burrow depth at Wild Harbor coincides with sediment depths where Reddy et al. (2002) and Peacock et al. (2005) first detect oil from the surface downward. In addition within oiled areas (TPHs content per core $>100 \mathrm{~g} \mathrm{~m}^{-2}$; Peacock et al., 2005), no U. pugnax burrows were found to reach depths greater than $14 \mathrm{~cm}$ in Wild Harbor (Fig. 3). Again, this concurs with Reddy et al. (2002) and Peacock et al. (2005), who generally found the highest oil concentrations to be at or near $12 \mathrm{~cm}$ (Fig. 3b). Photographs of representative burrow casts from each location are shown in Fig. 4c. As mentioned previously, Great Sippewissett marsh does not contain any detectable oil residues. Last, the observed depths of burrow casts at Great Sippewissett marsh are consistent with previous studies, in which burrows depths reached from 10 to $50 \mathrm{~cm}$ below the marsh surface (Krebs and Burns, 1977).

The shapes of the burrow casts suggested that $U$.pugnax not only detected the presence of oiled sediments but also halted or turned laterally to avoid the oiled sediments (Fig. 4b). In Wild Harbor, where we often had difficulty in removing the casts in one piece, 
the casts appeared to be curved and harder to follow below the marsh surface. In Great Sippewissett, the casts were much straighter and easier to remove (Fig. 4b).

To consider the effect of oil on the length of the burrow casts, we relied on the work of Peacock et al. (2005), who integrated the total amount of oil (as TPHs) in the top $24 \mathrm{~cm}$ in Wild Harbor (see Section 2.2). The most heavily contaminated sediment core in Peacock et al. (2005) contained $350 \mathrm{~g} \mathrm{TPH} \mathrm{m} \mathrm{m}^{-2}$ (integrated from 0-24 $\mathrm{cm}$ depth). For reference, the concentration of oil was highest at the 12 to $16 \mathrm{~cm}$ layer at this location and was $10.9 \mathrm{mg}$ of TPHs $\mathrm{g}^{-1}$ of dry sediment. When we compared burrow depth with the estimated oil content (using the aforementioned model), burrowing depth appeared to be shallower when the oil content was $75 \mathrm{~g} \mathrm{~m}^{-2}$ or greater (Fig. 4c). In Peacock et al. (2005), sediment cores that had total oil in this range typically contained oil concentrations of 2 to $5 \mathrm{mg}$ of $\mathrm{TPHs} \mathrm{g}^{-1}$ in either the 4 to 8,8 to 12 or 12 to $16 \mathrm{~cm}$ layers (Peacock et al., 2005). Despite our reliance on modeled estimates of oil content, we believe these ranges for biological effects may be a useful threshold for evaluating potential biological impacts, at least to crabs and related fauna.

The avoidance of petroleum residues made evident by the burrow casts suggested that there may be further behavioral effects, which we examined by comparing the escape responses and differences in feeding rate between crabs exposed and not exposed to oiled sediments

\subsection{Escape response}

Exposure to the petroleum hydrocarbons had acute $(<10 \mathrm{~d})$ and chronic $(>35 \mathrm{yrs})$ consequences for the escape response by $U$. pugnax. Crabs from Wild Harbor and Great Sippewissett both showed an acute response, in that crabs that fed for $10 \mathrm{~d}$ on sections of the oiled sediment (12-16 cm depth) were significantly slower to respond to the visual 
stimulus than those crabs that fed on non-oiled Great Sippewissett sediments at the same depth (t-test, t-stat=3.15, $P<0.001)$ (Table 1). There were no differences associated with feeding on near-surface (0-4 cm depth) or deeper layers of sediment (20-24 cm depth; Fig. 5a), so that differences in $\mathrm{N}$ content did not have any effect on escape response.

Chronic exposure to oil made Wild Harbor crabs considerably slower than Great Sippewissett crabs (t-test, $\mathrm{t}$-stat $=2.89, P<0.01$ ). This slower escape response was evident even in crabs that had not been feeding on the oiled sediment layer during the experimental period (Fig. 5a). The slope of a regression fitted to the data in Fig. 5a differed significantly from the 1:1 line $(\mathrm{F}=8.46, P<0.01)$, which points to a general depression of locomotor ability and greater sensitivity in $U$. pugnax chronically exposed to oil in Wild Harbor. Since we found it far easier to hand-collect crabs in Wild Harbor than in Great Sippewissett, we can anecdotally corroborate the slower escape responses of crabs from Wild Harbor. These results suggest that locomotor ability of crabs chronically exposed to oiled sediment in Wild Harbor were impaired compared to crabs from the non-oiled marsh. Exposed crabs were nevertheless still susceptible to oil; chronic exposure did not increase resistance to oil. This seems reasonable, since fiddler crabs have pelagic larvae, and hence the annual recruitment cohort does not necessarily have parents that were exposed to Wild Harbor oiled sediments (Montague, 1980).

\subsection{Feeding rate}

There was also an acute feeding response to oil; crabs from both Great Sippewissett and Wild Harbor fed more slowly when exposed to the oiled sediment layer than when fed on non-oiled sediments (t-test, t-stat $=-10.40, P<0.001)$. Note that in Fig. 5 b, all points fell below the 1:1 line. There was no apparent chronic feeding response by Wild Harbor crabs to the oil, since feeding rates for Wild Harbor crabs were not statistically different than 
those of Great Sippewissett crabs $(\mathrm{F}=1.853, P>0.05)$ (Fig. 5b). The slope of a regression fitted to the data in Fig. 5b, and the intercept, were not significantly different than those of the 1:1 line (not shown). There were no differences in $\% \mathrm{~N}$ between sites at depth.

\subsection{Abundance}

To evaluate whether the short and long-term behavioral effects translated into population-level impacts, we surveyed abundance of $U$. pugnax in each of the two marshes (Krebs and Valiela, 1978). Using previous work to compare the number of burrows to the number of fiddler crabs present $\left(\mathrm{m}^{-2}\right)$ (Krebs and Valiela, 1978), we found that the median density of $U$.pugnax in Wild Harbor was less than half that found in the control marsh (Fig. 6). Moreover, there was a noticeable skew in the abundances, with significantly more low values in Wild Harbor $\left(\chi^{2}=21.64, P<0.01\right)$. Both these features point to the relative scarcity of $U$. pugnax in the oiled marsh compared to the non-oiled marsh. The lower abundance of $U$. pugnax in Wild Harbor compared to Great Sippewissett is consistent with the notion that the short- and long-term locomotor impairment may increase exposure of $U$. pugnax to the abundant predators found in the salt marsh ecosystem.

The results of the behavioral and field studies suggest that the petroleum residue still present almost forty years after the Florida spill continues to have biological effects. Crabs collected in the marsh with oiled sediments made shallower burrows, exhibited slowed escape responses in the short-term, as well as exhibited a long-term effect, and displayed a short-term lowering of feeding rates compared to crabs from a non-oiled marsh. The responses that we documented paralleled results of similar work done soon after the original spill, indicating slower escape response, shallower burrowing depth and decreased abundances in oiled areas versus non-oiled areas (Krebs and Burns, 1977). Therefore, 
long-term exposure not only does not lead to a build-up of resistance, but may chronically impair crab behavior.

Since most animals do not penetrate 8 to $20 \mathrm{~cm}$ into the sediment, we are unsure how the lingering effects reported here may affect other members of the salt marsh food web. The non-oiled surface layer might, in fact, be responsible for the relatively unaffected appearance of the salt marsh. Burial of the spilled oil probably reduces exposure. The results presented here, however, do show that the buried oil residues are still biologically active, and does have harmful long-term effects on populations that manage to reach the contaminated layer, such as U. pugnax.

The decrease in $U$. pugnax densities may lead to larger-scale ecosystem effects. Fiddler crab populations are an integral part of the salt marsh food web. Fiddler crabs are ecologically important invertebrates in many salt marshes on the east coast (Daiber, 1982). Their activities and by-products affect the transfer of energy and nutrients within the marsh ecosystem (Daiber, 1982; Teal, 1962), biomass of salt marsh vegetation by increasing soil drainage and aeration (Krauter, 1974), and are important in sediment turnover, which leads to important nutrient transformations within the salt marsh and in neighboring coastal areas (Teal, 1962). The effect of the residual oil on the decline of $U$. pugnax populations is therefore likely to result in decreased aeration and lower grass production in the salt marsh ecosystem.

In summary, recovery from oil spills depends on the species, on the post-spill history, and on characteristics of the specific environment (Baker, 1999). In anoxic accreting salt marshes that have been exposed to spilled oil the residual undegraded biologically active oil may last for many decades with the potential for chronic lingering effects. Information on such effects is essential when determining whether to restore, 
rehabilitate, or replace oil-impacted areas, as required under legislation enacted in many countries, such as the United States Oil Pollution Act of 1990 (33 U.S.C. 2701-2761). It is evident that we need more than mere visual inspection of environments or chemical analysis of coastal environments to evaluate recovery of oil-impacted areas.

\section{Acknowledgments}

This work was funded by a grant from the Woods Hole Oceanographic Institution Sea Grant Program, under grants from the National Oceanic and Atmospheric Administration, U.S. Department of Commerce, under Grant No. NA16RG2273, project no. R/P-73. Additional support was provided by funding from the NSF funded Research Experience for Undergraduates program, award 0453292, an Office of Naval Research Young Investigator Award (N00014-04-01-0029) to C. Reddy, and an USEPA Science to Achieve Results Graduate Fellowship (FP91661801) to E. Peacock. The authors thank Helen White, Bob Nelson, Li Xu, Ylva Olsen, Nadine Lysiak and D. B. Madison for assistance with data collection and analysis. Thanks to Robert I. Haddad (Applied Geochemical Strategies, Inc.), John Farrington, and John Teal for reviewing earlier drafts of this manuscript. We also thank the Bayshores Homeowners for site access and the Ford family for their hospitality and support.

\section{References}

Baker, J. M., 1999. Ecological effectiveness of oil spill countermeasures: How clean is clean? Pure Applied Chemistry 71,135-151.

Blumer, M., Sass, J., Souza, G., Sanders, H. L., Grassle, J. F., Hampson, G. R., 1970. The West Falmouth oil spill - The persistence of the pollution eight months after the 
accident. Woods Hole Oceanographic Institution Technical Report 70-44.

Blumer, M., Sass, J., 1972a. Oil pollution: Persistence and degradation of spilled fuel oil. Science 176, 1120-1122.

Blumer, M, Sass, J, 1972b. Indigenous and petroleum-derived hydrocarbons in a polluted sediment. Marine Pollution Bulletin 3, 92-94.

Burns, K. A., Teal, J. M., 1971. Hydrocarbon incorporation into the salt marsh ecosystem after the West Falmouth oil spill. Woods Hole Oceanographic Institution Technical Report 71-69.

Daiber, F. C., 1982. Animals of the Tidal Marsh. Van Nostrand Reinhold, New York.

Frysinger, G.S., Gaines, R.B., Reddy, C.M., 2002. GC_GC: A new analytical tool for environmental forensics. Environmental Forensics 3, 27-34.

Krauter, J. N., Wolf, P. L., 1974. In Ecology of Halophytes Reimold, K. J., Queen, W. H., Eds., Academic Press, New York, pp. 449-462.

Krebs, C. T., Burns, K. A., 1977. Long-term effects of an oil spill on populations of the salt-marsh crab Uca pugnax. Science 197, 484-487.

Krebs, C. T., Valiela, I., 1978. Effects of experimentally applied chlorinated hydrocarbons on the biomass of the fiddler crab, Uca pugnax. Estuarine and Coastal Marine Science 6, 375-386.

Long, E. R., MacDonald, D. D., Smith, S. L., Calder, F. D., 1995. Incidence of adverse 
biological effects within ranges of chemical concentrations in marine and estuarine sediments. Environmental Management 19, 81-97.

Montague, C. L., 1980. A natural history of temperate western Atlantic fiddler crabs (genus $U c a$ ) with reference to their impact on the salt marsh. Contribution in Marine Science 23, 25-55.

National Research Council of the National Academies, 2003. Oil in the Sea III; The National Academies Press, Washington, D.C.

Peacock, E. E., Nelson, R. K., Solow, A. R., Warren, J. D., Baker, J. L., Reddy, C. M., 2005. The West Falmouth oil spill: $~ 100 \mathrm{~kg}$ oil found to persist decades later. Environmental Forensics 6, 273-281.

Peacock, E. E., Hampson, G. R., Nelson, R. K., Li, X., Frysinger, G. S., Gaines, R. B., Farrington, J. W., Tripp, B. W., Reddy, C. M., 2007. The 1974 spill of the Bouchard 65 oil barge: Petroleum hydrocarbons persist in Winsor Cove salt marsh sediments. Marine Pollution Bulletin 54, 214-225.

Peterson, C. H., Rice, S. D., Short, J. W., Ester, D., Bodkin, J. L., Ballachey, B. E., Irons, D. B., 2003. Long-term ecosystem response to the Exxon Valdez oil spill. Science 302, 2082-2086.

Reddy, C. M., Eglinton, T. I., Hounshell, A, White, H. K., Xu, L., Gaines, R. B., 
Frysinger, G.S., 2002. The West Falmouth oil spill: The persistence of petroleum hydrocarbons in marsh sediments. Environmental Science and Technology 36, 4754-4760.

Sanders, H. L., Grassle, J. F., Hampson, G. R., 1972. The West Falmouth oil spill. I. Biology. Woods Hole Oceanographic Institution Technical Report 72-20. Slater, G. F., White, H. K., Eglinton, T. I., Reddy, C. M., 2005. Determination of microbial carbon sources in petroleum contaminated sediments using molecular ${ }^{14} \mathrm{C}$ analysis. Environmental Science and Technology 39, 2552-2558.

Teal, J. M., 1962. Energy flow in the salt marsh ecosystem of Georgia. Ecology 43, 614-624.

Teal, J., Burns, K., Farrington, J., 1978. Analyses of aromatic hydrocarbons in intertidal sediments resulting from two oil spills of No. 2 fuel oil in Buzzards Bay, Massachusetts. Journal of the Fisheries Research Board of Canada 35, 510-520.

Teal, J. M., Farrington, J. W., Burns, K. A., Stegeman. J. J., Tripp, B. W., Woodin, B., Phinney, C., 1992. The West Falmouth oil spill after 20 years: Fate of fuel oil compounds and effects on animals. Marine Pollution Bulletin 24, 607-614.

Valiela, I., 1995. Marine Ecological Processes. Springer-Verlag, New York. 
White, H.K., Reddy, C.M., Eglinton, T.I., 2005a. Isotopic constraints on the fate of petroleum residues sequestered in salt marsh sediments. Environmental Science and Technology 39, 2545-2551.

White, H. K., Xu, L., Lima, A. L. C., Eglinton, T. I., Reddy, C. M., 2005b. Abundance, composition, and vertical transport of PAHs in marsh sediments. Environmental Science and Technology 39, 8273-8280. 


\section{Figure legends}

Fig. 1. Image of the Florida barge run aground in Buzzards Bay, MA, September 1969, with permission from the New Bedford Standard-Times (Maps of the spill area are available in Reddy et al. (2002).

Fig. 2. Images from Wild Harbor: ( $a$ and b) Dead fauna on the wrack zone of Wild Harbor, taken soon after the spill occurred in 1969 (Photo by I. Valiela). (c) Wild Harbor marsh as it appeared in 2005 (Photo by H. White).

Fig. 3. Uca pugnax burrow depths in Wild Harbor. (a) Number of fiddler crab burrows of different depths in Wild Harbor. (b) Concentration of total petroleum hydrocarbons (TPHs) at different depths in a core of sediment from an oiled area of Wild Harbor (Reddy et al., 2002). (c) Burrow depth in Wild Harbor compared to estimated concentrations of TPHs $\left(\mathrm{g} \mathrm{oil} \mathrm{m}^{-2}\right) \mathrm{using}$ modeled data (Peacock et al., 2005), $\mathrm{y}=-0.0398 \mathrm{x}+13.197, \mathrm{~F}=100.94^{* * *}, R^{2}=0.8$.

Fig. 4. (a) Number of Uca pugnax burrows of different depths recorded in Wild Harbor (left) and in Great Sippewissett (right), $\chi^{2}=21.64^{* *}$. (b) Image of Wild Harbor burrow casts (left) and Great Sippewissett burrow casts (right).

Fig. 5. Behavioral responses in U. pugnax from oiled (Wild Harbor, W) and non-oiled (Great Sippewissett, G) locations when exposed to oiled (in bold) and non-oiled sediments. (a) Escape response of Wild Harbor crabs and Great Sippewissett crabs when fed sediment from various depths at Wild Harbor and Great Sippewissett. (b) Feeding rate of Wild Harbor crabs and Great Sippewissett crabs fed sediment from various depths at Wild Harbor and Great Sippewissett.

Fig. 6. Frequency distribution of burrow density (a proxy for crab density) in Wild Harbor and in Great Sippewissett marshes. 
Table 1. Escape responses (time to leave a circle of $22 \mathrm{~cm}$ radius, in seconds, mean \pm s.e.) of $U$. pugnax from oiled (Wild Harbor, W) and non-oiled (Great Sippewissett, G) locations when exposed to oiled (in bold) and non-oiled sediments from various depths.

\begin{tabular}{ccccc} 
Crab source & \multicolumn{2}{c}{ W } & \multicolumn{2}{c}{ G } \\
\cline { 1 - 4 } Sed. source & W & G & W & G \\
\cline { 1 - 4 } Depth $(\mathrm{cm}):$ & & & & \\
$0-4$ & $5.8 \pm 1.5$ & $6.6 \pm 3.0$ & $2.6 \pm 0.6$ & $1.7 \pm 0.2$ \\
$12-16$ & $\mathbf{2 0 . 1 \pm 7 . 7}$ & $3.4 \pm 0.9$ & $\mathbf{4 . 8} \pm \mathbf{1 . 0}$ & $2.0 \pm 0.3$ \\
$20-24$ & $8.6 \pm 4.7$ & $2.8 \pm 0.7$ & $3.0 \pm 1.0$ & $1.0 \pm 0.1$
\end{tabular}


Table 2. Feeding rate responses (mean number of fecal pellets $12 \mathrm{hrs}^{-1} \mathrm{crab}^{-1}$ ) of $U$. pugnax from oiled (Wild Harbor, W) and non-oiled (Great Sippewissett, G) locations when exposed to oiled (in bold) and non-oiled sediments from various depths.

\begin{tabular}{|c|c|c|c|c|}
\hline Crab source & \multicolumn{2}{|c|}{ W } & \multicolumn{2}{|c|}{ G } \\
\hline Sed. source & W & G & W & $\mathrm{G}$ \\
\hline Depth $(\mathrm{cm}):$ & & & & \\
\hline $0-4$ & $13.5 \pm 1.0$ & $12.1 \pm 0.8$ & $12.0 \pm 0.7$ & $13.0 \pm 0.7$ \\
\hline $12-16$ & $2.0 \pm 0.2$ & $6.7 \pm 0.8$ & $1.7 \pm 0.2$ & $6.4 \pm 0.4$ \\
\hline $20-24$ & $6.2 \pm 0.5$ & $4.4 \pm 0.5$ & $4.9 \pm 0.5$ & $4.5 \pm 0.5$ \\
\hline
\end{tabular}


Fig. 1

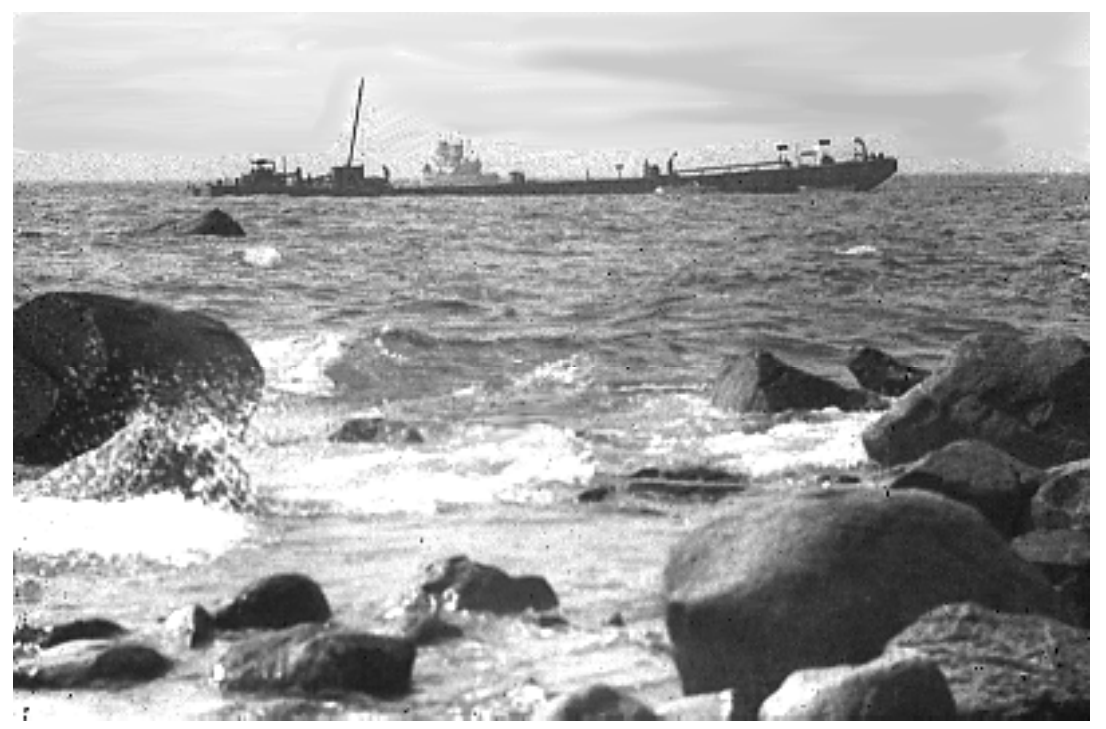


Fig. 2
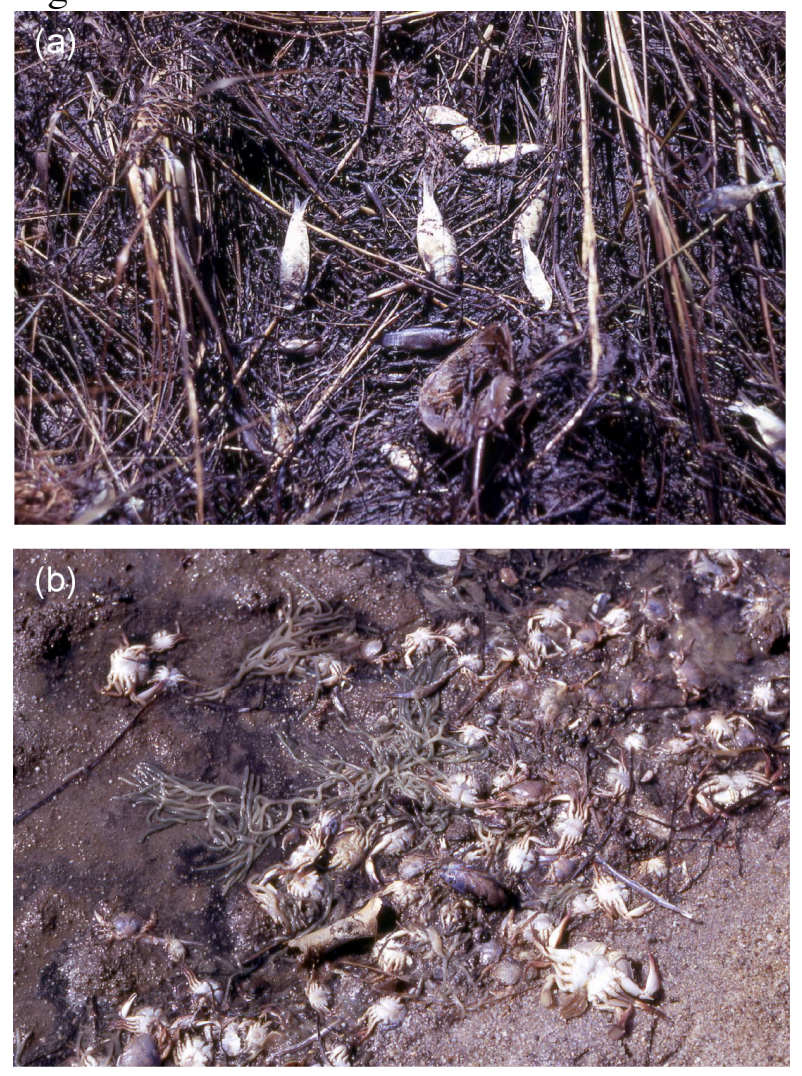

(c)

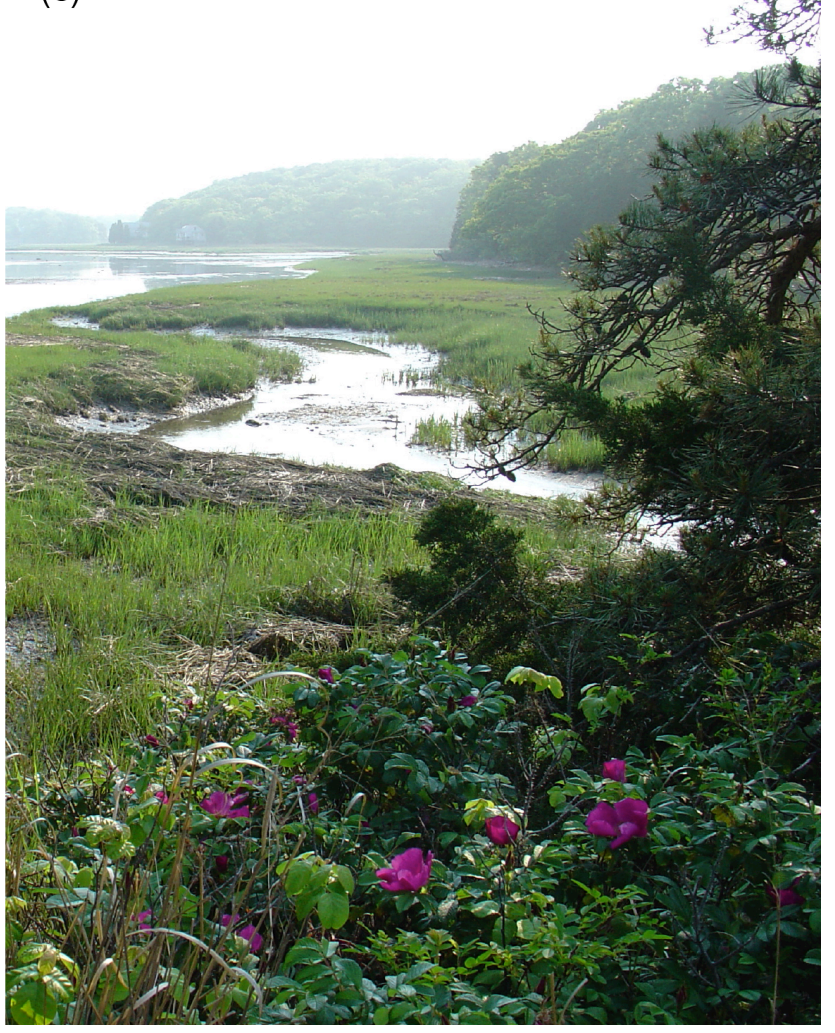




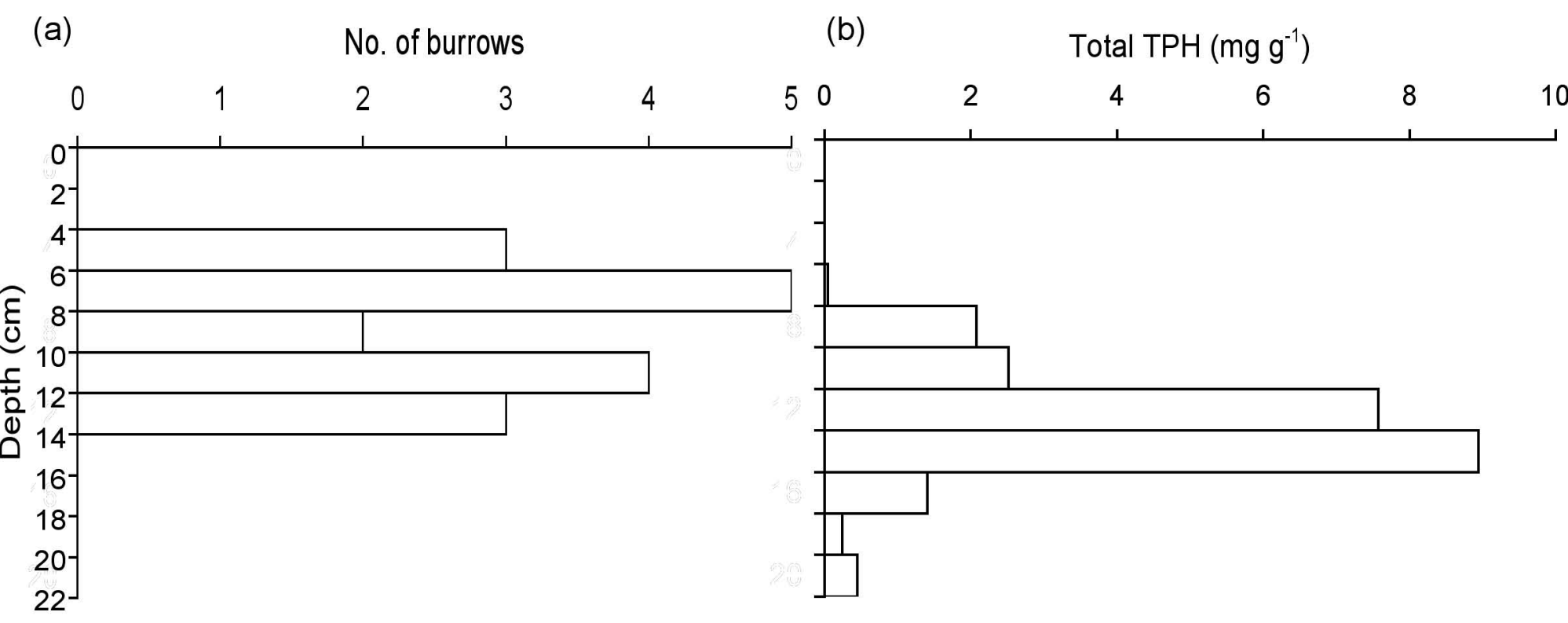

(c)

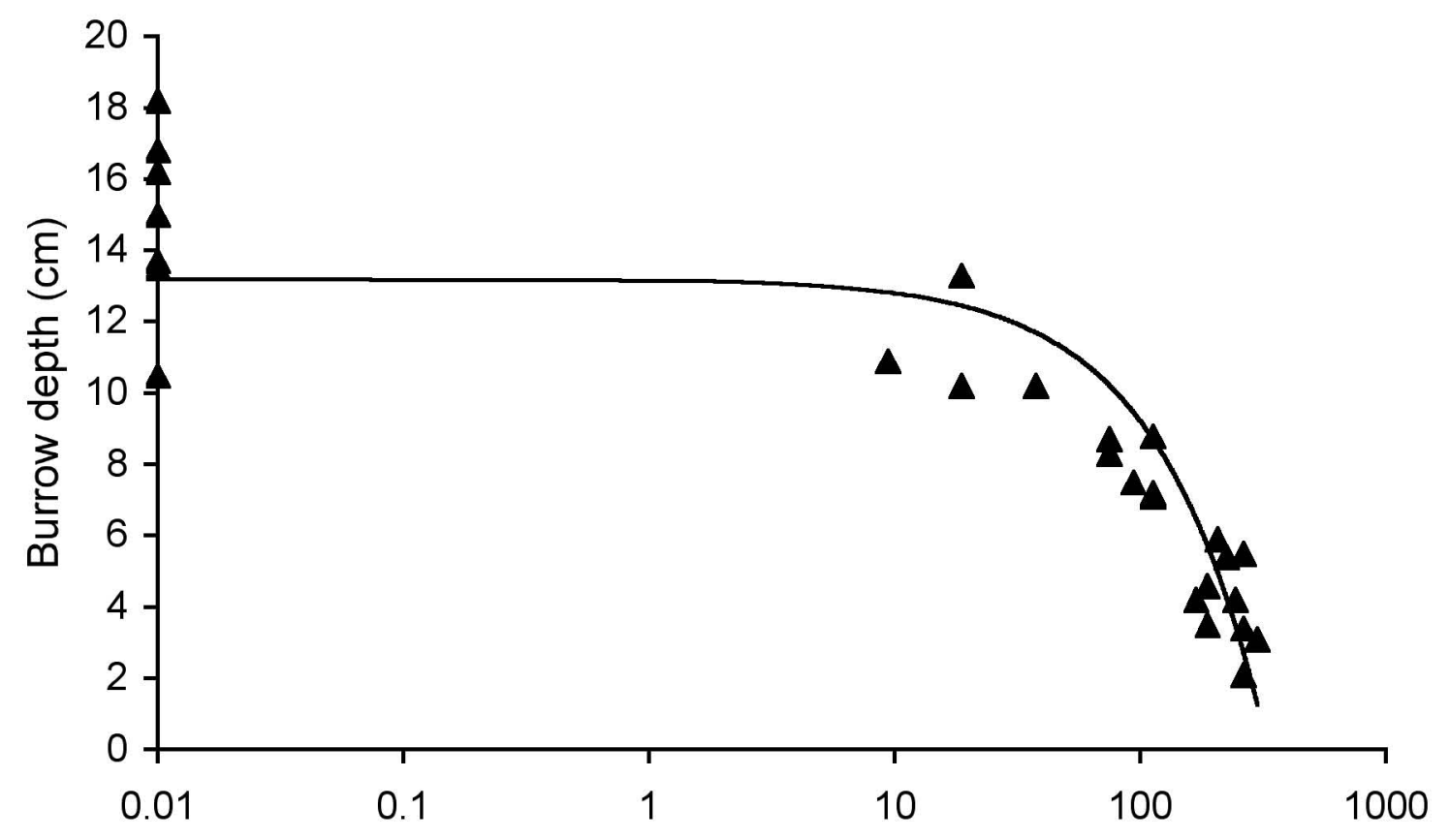

Estimated oil content $\left(\mathrm{g} \mathrm{m}^{-2}\right)$ in Wild Harbor marsh in top $24 \mathrm{~cm}$ as modeled by Peacock et al. (2005) 
Fig. 5

a ESCAPE RESPONSE

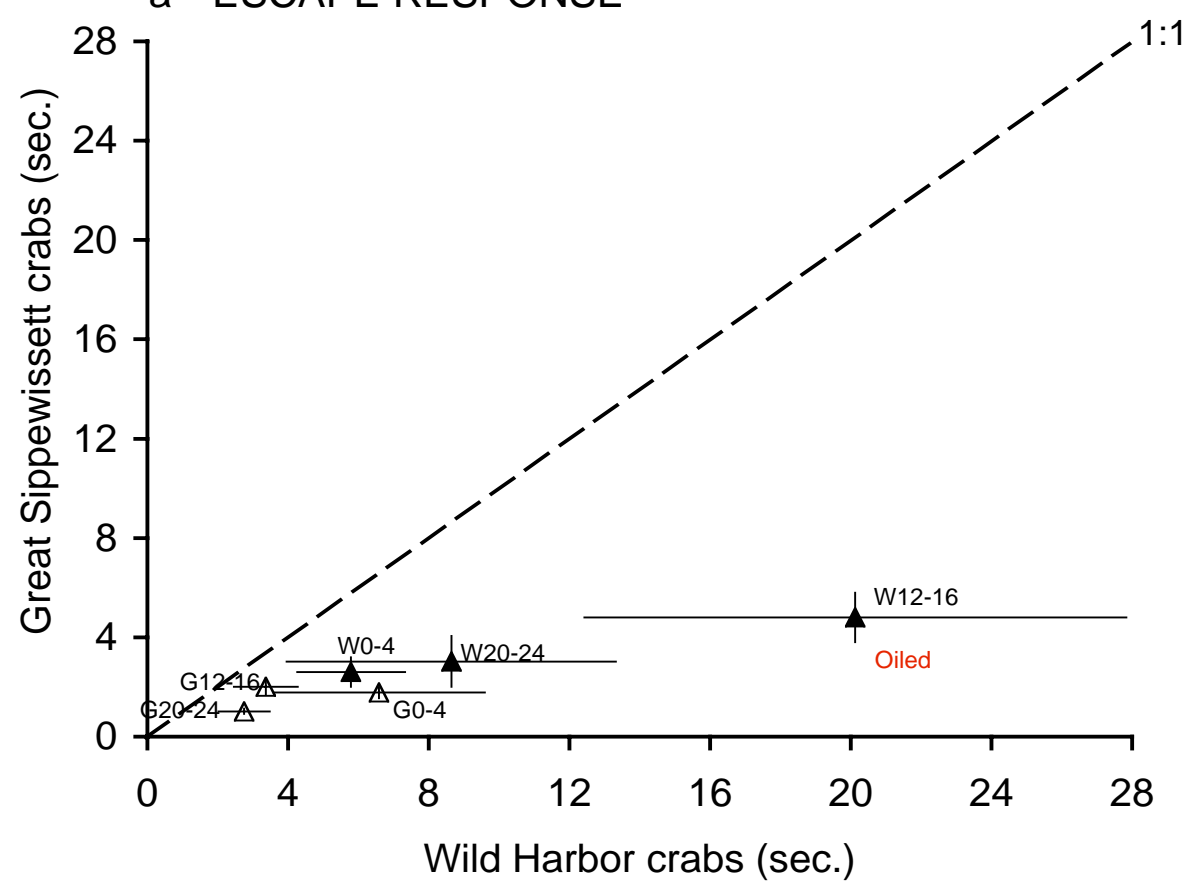

b FEEDING RATE

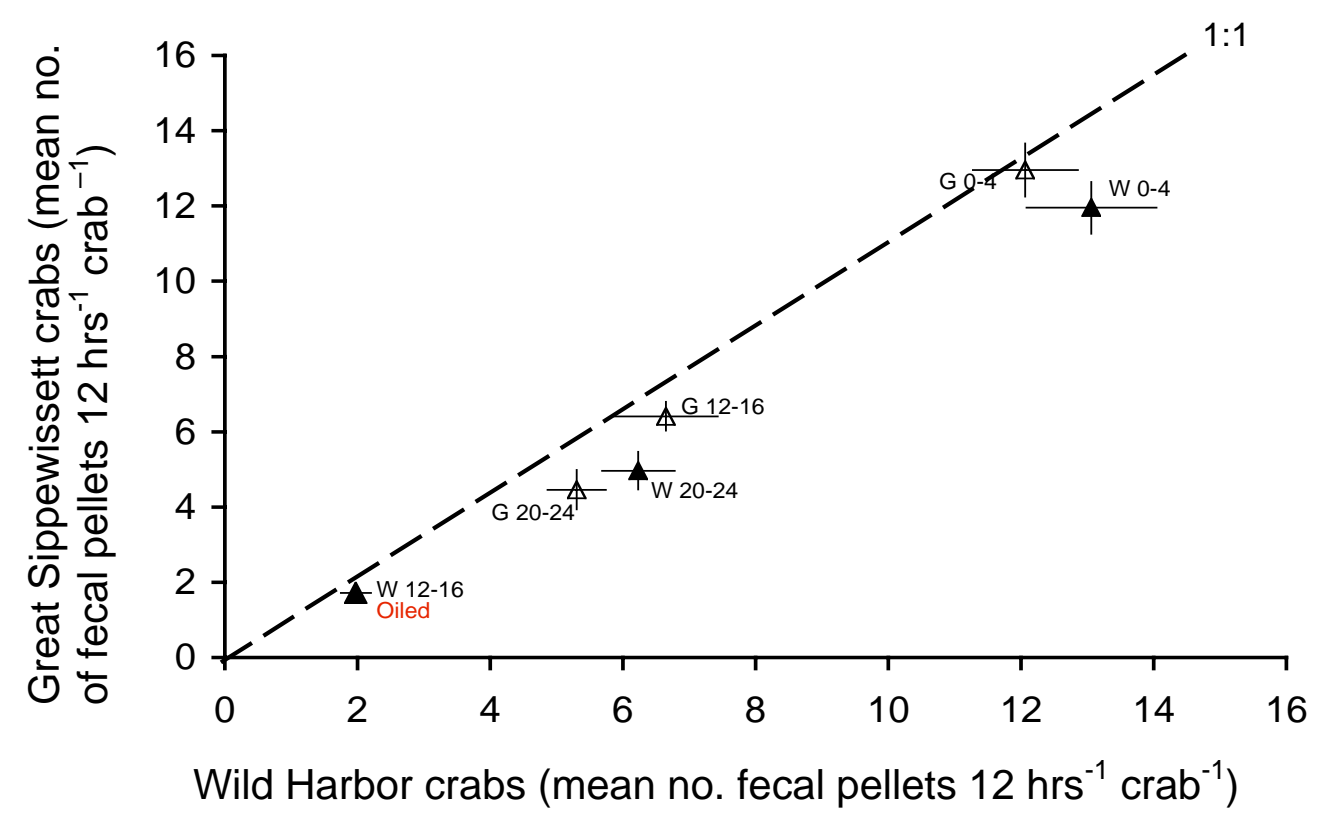


Fig. 6

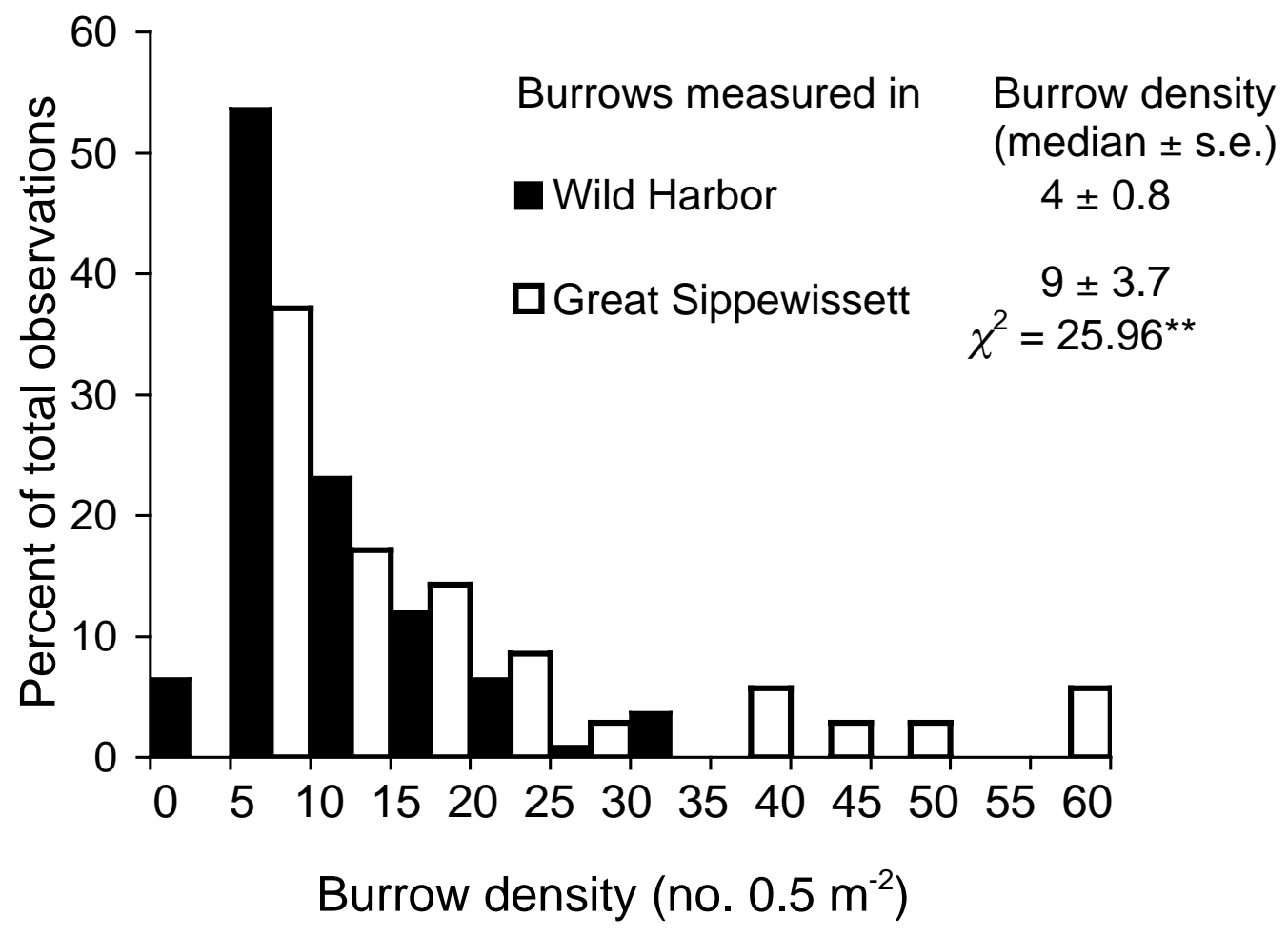

